\title{
Is blood pressure different in black people?
}

\author{
Herbert G. LANGFORD \\ M.D.
}

Department of Medicine, University of Mississippi Medical Centre, Jackson, Mississippi, U.S.A.

\begin{abstract}
Summary
Most studies show that blacks have higher blood pressures than whites, and that hypertension-related mortality is significantly greater. Significant pathophysiological differences are present, on the average, between blacks and whites. Blacks tend to have higher blood volume, lower plasma renin activity, and lower kallikrein excretion.
\end{abstract}

While there may be black-white differences of genetic origin affecting the prevalence of hypertension, at least part of blood pressure difference between black and white is probably of environmental origin.

If socio-economic differences are taken into account, there is no difference between black and white in compliance. Antihypertensive therapy markedly reduces mortality in blacks as well as whites.

\section{Introduction}

Blacks have higher blood pressure than do whites. What are the causes? Blacks die from hypertension more rapidly than do whites. What can we do at least to equalize the toll? How much of these differences is environmental, how much-if any-is genetic? In this paper answers to these questions are sought, and the question is asked as to whether the racial differences give clues to the cause of hypertension in all people, black or white.

\section{Differences in blood pressure}

In the U.S.A., almost every comparison of blackwhite blood pressures has revealed higher blood pressures in blacks. The magnitude of differences vary. The ratio of black to white hypertension is probably higher in the South of the U.S.A., a hypertension prevalence area, than in the North where hypertension is less common. The blackwhite differences in blood pressure are not unique to the United States of America. In London, it was found that black hypertensive patients had higher blood pressures than did white hypertensive patients (Sever et al., 1978). Selective referral and admission patterns could have resulted in the apparent differ- ence between the races. Casting doubt on the universal truth of the dogma that blacks have higher blood pressures than whites, Cruickshank and Beevers (1980) found that blacks in Jamaica had essentially the same blood pressures as did white factory workers in Birmingham, England. The report of the Hypertension Detection and Follow-Up Program (HDFP) Cooperative Group (1977) on its initial screening results is an example of the marked difference in hypertension prevalence. In the first phase of the HDFP, blood pressures were taken at home in more than 150000 individuals aged 39-69 years throughout the United States of America. Using a definition for 'actual hypertensives' which summed those with sitting diastolic blood pressure $\geqslant 95 \mathrm{mmHg}$, and those on antihypertensive medication, the percentage of blacks defined as hypertensive was $37 \%$, compared to $18 \%$ of whites (HDFP Cooperative Group, 1977). The rate of severely elevated blood pressure (diastolic $\mathrm{BP} \geqslant 115 \mathrm{mmHg}$ ) was about 6 times higher for blacks.

Socio-economic and place-of-residence effects on blood pressure of blacks and whites

The HDFP used 'years of education' as the only available indicator of socio-economic status and correlated this variable with blood pressure. In the 4 race-sex groups there was significant inverse correlation between years of education and blood pressure. On average, the person with less than 10 years of education was twice as likely to be hypertensive as the college graduate. At each level of education, the black was twice as likely to be hypertensive as the white. However, when only individuals with a weight equal to 1 to 1.9 times ideal BP were considered, the influence of education on weight was abolished with the exception of black men (HDFP Cooperative Group, 1977).

The influence of socio-economic status on blood pressure has been noted a number of times. In Mississippi, the blood pressure of urban high school children was negatively correlated with the 
income status of their family, and the blood pressure of high school children from the surrounding rural county was higher than that of individuals from the lowest socio-economic group in the city. If the black urban children from the highest socio-economic group were compared with rural white boys, the usual black-white difference was reversed; rural white children had significantly higher systolic pressure than did upper socio-economic black children. When the same comparison was done for the girls, the black-white difference was abolished, but not reversed (Fig. 1) (Langford, Watson and Douglas, 1968).

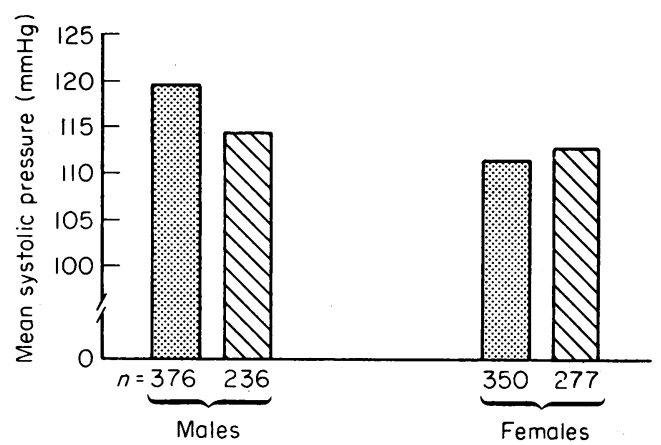

FIG. 1. Mean systolic pressure for rural white 0 and upper socio-economic status city Negro students

While obesity contributed somewhat to the socio-economic gradient observed, the findings remained even after adjustment for it. The findings of some environmental effect on blood pressure can be seen on a national scale in the United States of America where the blood pressures of both blacks and whites are lower in the North than the South, and probably lower in the far West than in either of the 2 areas.
It is apparent that there are strong environmental effects on blood pressure, and the question of $a_{c}$ genetic black-white difference may be impossible to $\Rightarrow$ address until the nature of these environmentalos forces is identified and quantitated.

Pathogenetic mechanisms for the correlation between $\frac{\overline{\bar{c}}}{\frac{7}{\sigma}}$ environment and blood pressure

Three types of explanations for the environ-0 mental effect on blood pressure can be visualized. Psychic stress is one mechanism. Mortality from? hypertension appears to correlate with indices of $\vec{\omega}$ social disorganization, such as divorces, jailings, ando other brushes with the law. However, the correlation: is not with blood pressure (James and Kleinbaum 3 . 1976). Harburg, in his extremely careful studies incr Detroit, found some correlation between social $\%$ stress and elevated blood pressure (Harburg et al., $+\vec{D}$ 1977). This correlation was weak and not present through all groups.

The degree of obesity may well be a factor in the은 environmental influences on blood pressure. As noted above in the HDFP, most of the effect of education on blood pressure was removed when subjects near ideal weight were considered. Black men were the exceptions to this rule. Hypertension was still twice as common in blacks as in whites ot $\overrightarrow{.}$ ideal weight; clearly this is not the major explanationo for black-white differences in blood pressure.

Differences in electrolyte consumption between. the races and between the various socio-economic groups is an attractive and incompletely tested idea.ō In Mississippi, 20-year-old black girls have higher:̊ำ pressures than do 20-year-old white girls of theo same weight. The black girls have somewhat higher $\overrightarrow{\vec{O}}$ sodium intakes, considerably lower potassium 3 intakes and, therefore, clearly lower sodiumpotassium ratios calculated from urinary excretion? (Table 1). As there is a considerable body of datao suggesting that the dietary sodium/potassium ratio correlates with blood pressure, this finding would

TABLE 1. Mean blood pressure, weight, and urinary solute excretion rates $/ 24 \mathrm{hr}$ for black females and white females

\begin{tabular}{|c|c|c|c|c|c|c|c|}
\hline \multirow[t]{2}{*}{ Measurement } & \multicolumn{3}{|c|}{1968 and 1969 black females } & \multicolumn{3}{|c|}{1970 white females } & \multirow[b]{2}{*}{$t$} \\
\hline & $n$ & mean & sd & $n$ & mean & sd & \\
\hline $\begin{array}{l}\text { Home measurement } \\
\text { Weight (kg) } \\
\text { Systolic BP (mmHg) } \\
\text { Diastolic BP (mmHg) }\end{array}$ & $\begin{array}{c}506 \\
506 \\
506\end{array}$ & $\begin{array}{r}57 \cdot 2 \\
116 \cdot 0 \\
70.7\end{array}$ & $\begin{array}{l}12.0 \\
11.7 \\
11.6\end{array}$ & $\begin{array}{l}82 \cdot 3 \\
181 \\
181\end{array}$ & $\begin{array}{r}57 \cdot 1 \\
109 \cdot 1 \\
69 \cdot 3\end{array}$ & $\begin{array}{r}9 \cdot 7 \\
9 \cdot 0 \\
13.0\end{array}$ & $\begin{array}{l}0 \cdot 07 \\
8 \cdot 14^{*} \\
1 \cdot 28\end{array}$ \\
\hline $\begin{array}{l}\text { 24-hr urine } \\
\mathrm{Cr} \\
\mathrm{Ur} \\
\mathrm{Na} \\
\mathrm{K} \\
\mathrm{Na} / \mathrm{K}\end{array}$ & $\begin{array}{l}355 \\
107 \\
356 \\
356 \\
356\end{array}$ & $\begin{array}{r}3 \cdot 5 \\
99 \cdot 2 \\
112 \cdot 8 \\
28 \cdot 8 \\
98 \cdot 4\end{array}$ & $\begin{array}{r}2 \cdot 7 \\
30 \cdot 8 \\
48 \\
9 \cdot 6 \\
40 \cdot 8\end{array}$ & $\begin{array}{l}104 \\
104 \\
104 \\
104 \\
104\end{array}$ & $\begin{array}{r}9 \cdot 1 \\
110 \cdot 5 \\
98 \cdot 4 \\
36 \\
69 \cdot 6\end{array}$ & $\begin{array}{l}2 \cdot 1 \\
39 \cdot 1 \\
28 \cdot 8 \\
12 \\
24\end{array}$ & $\begin{array}{r}0 \cdot 6^{*} \\
0 \cdot 9^{*} \\
90 \cdot 9^{*} \\
127 \cdot 7^{*} \\
20 \cdot 4^{*}\end{array}$ \\
\hline
\end{tabular}


seem to explain at least some of the black-white difference (Watson et al., 1980).

\section{Correlation between genes characteristic of black individuals and hypertension}

If the greater frequency and severity of hypertension in the blacks is of genetic origin, then it follows that individuals who are of completely African ancestry should have higher blood pressures than those carrying mixed genes. Several papers have addressed this question. McLean reported a significant correlation between the frequency of genes characteristic of blacks and blood pressure (McLean et al., 1974). When Boyle (1970) studied blacks in Charleston, South Carolina, and the surrounding islands, he reported that there was a direct correlation between blackness of skin and elevated blood pressure. However, when a follow-up study correlated blood pressure in relation to both skin colour and social class, there was marked attenuation if not complete disappearance of the correlation

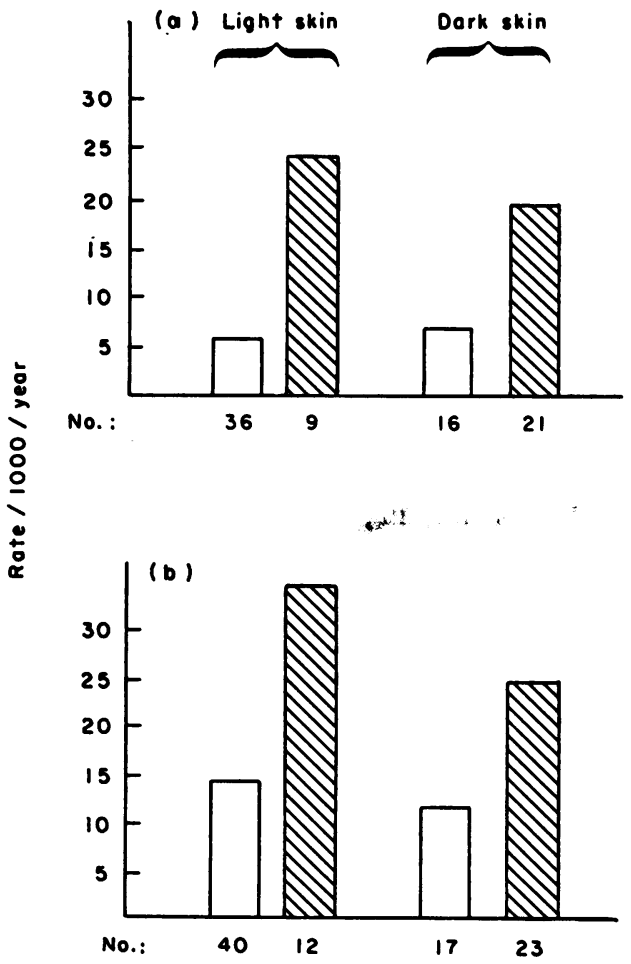

Fig. 2. Frequency distribution of socio-economic status among black males in Charleston County, South Carolina Heart Study (HDFP Cooperative group, 1979) $\square$, high social class; $\mathbb{N}$, low social class. (a) Excluding subjects on antihypertensive therapy; (b) including subjects on antihypertensive therapy. Incidence rate of hypertension $=$ no. of cases adjusted for follow-up period and indirect age adjusted; expressed as rate/1000/year. Normotension $\leqslant$ 139 and $\leqslant 84$; hypertension $\geqslant 150$ and $\geqslant 90$.
(Fig. 2) (Keil et al., 1977). A correlation did remain between skin colour and blood pressure in individuals selected by their peers as leaders of the black community. However, even here it is impossible to rule out present or early socio-economic status as the important variable.

As there is a significant correlation between light skin and upper social class among U.S.A. blacks, it seems likely that any correlation found with genes characteristic of Africans can be explained as a social class effect, not a primarily genetic one.

\section{Pathophysiological abnormalities and black-white contrasts in hypertension}

One of the earliest reports on plasma renin activity in hypertension pointed out that suppressed plasma renin activity was much more common in blacks (Helmer and Judson, 1968). This finding of frequent 'low renin hypertension' in blacks has been one of the sturdier abnormalities to date; all studies using a variety of techniques to stimulate renin secretion and ways to measure renin have confirmed the original observation. Two other abnormalities have been associated in some studies: blacks had a higher relative plasma volume than did whites (Mitus et al., 1979), and excreted less urinary kallikrein after sodium depletion (Levy et al., 1977).

One study showed lower plasma noradrenaline in black males than white males (Jones, Hamilton and Reid, 1978) but no difference between females. Plasma dopamine $\beta$-hydroxylase activity was significantly lower in blacks than in whites (Levy, Frigon and Stone, 1979).

In addition, it has been reported that blacks excrete a salt load more slowly than do whites (Luft et al., 1977). Furthermore, heart-rate was higher in white children from highest blood pressure strata than in black children from the same strata (Voors et al., 1979).

The interpretation of these multiple black-white differences is not immediately clear. The evidence can be interpreted to mean that black patients are more likely to have volume overload hypertension. Although one study has shown an excess of adrenal adenoma at post-mortem in young black men dying of accelerated hypertension (Russell, Mari and Richter, 1972), measurements of plasma aldosterone have not shown a significant difference between the races. If anything, there is a tendency for somewhat lower aldosterone concentrations in some of the low renin hypertensive patients, a finding compatible with the evidence that at least some blacks have difficulty in excreting sodium. Levy et al. (1978) found no difference in glomerular filtration rate but found renal plasma flow significantly lower in black patients. They also detected significantly more 
renal arterial disease characterized by blunting of the renal arteries in the blacks.

\section{Black-white differences in sodium economy}

An attractive hypothesis to explain black-white differences in blood pressure is to postulate that the black is innately more thrifty with sodium than the white as a consequence of an evolutionary history in a sweating, salt-poor tropical climate, compared to the white's descent from ancestors living in a more frigid, salt-replete environment. Except for the studies on renal response to salt loads, there have been no studies to test this hypothesis, although one report of black and white adaptation to heat has been interpreted as showing that blacks sweat less than whites when working in a hot environment. The data in the original paper are not adequate to use as a base for such an interpretation.

\section{Racial differences in cardiovascular consequences of hypertension}

The statement 'hypertension is worse in blacks' has been interpreted in 2 ways. As hypertension is much more frequent in blacks than in whites, many more blacks will be at risk for the cardiovascular consequences of hypertension. However, an associated implication which has been accepted by many is that the same amount of blood pressure elevation produces more disease in blacks than in whites. Here the evidence is unclear. The first paper in which this question was considered systematically was from the continuing study in Evans County, Georgia. There, the individual attributable risk from hypertension was less for black than for white men (Deubner, Tyroler and Cassell, 1975). Ashcroft and Desai (1978) found correlation in Jamaicans with total mortality only over $180 / 110 \mathrm{mmHg}$ (phase IV) [approximately equivalent to $180 / 104 \mathrm{mmHg}$ (phase V)]. Cruickshank and Beevers (1980) found that blacks in Birmingham, England, had fewer heart attacks than would have been anticipated, but a higher admission rate for stroke.

On the other hand, proteinuria is more frequent in black hypertensive patients than in whites even after blood pressure is taken into account. Also in the HDFP, ECG abnormalities were more frequent in blacks than whites after correction for blood pressure.

The picture is further clouded by the difficulty in specifying comparable blood pressures when comparing individuals from 2 populations with different mean pressures and different distribution of blood pressures. Regression to the mean will be greatest in an individual who is furthest from the group mean. Therefore, a hypertensive white will be further from the group mean of the whites and will have greater regression to the mean. Unless regression to the mean is taken into account, it is likely that at al times individuals from the group with the highest group mean will have the greatest amount of end organ damage when compared to individuals from the contrasting group, with a lower group mean.

It seems likely that in blacks, as in whites, the degree of end-organ damage will be a function not $\overline{\overline{\bar{s}}}$. only of the individual's blood pressure elevation $\bar{\varnothing}$ but of the other risk factors. Therefore, in the present state of knowledge, it can be said that if individuals ${ }^{\infty}$ are classified by their blood pressure after regression? to the mean has been taken into account, end-organ $\overrightarrow{\vec{\omega}}$ damage will be a function of blood pressure and $\omega_{\sigma}$ the other cardiovascular risk factors, which will not? include skin colour or race.

\section{Response to antihypertensive therapy}

Black patients usually respond much better to diuretic therapy than to $\beta$-blocker therapy as would $\sim$ be expected from the high percentage of blacke hypertensives that are 'low-renin'.

Compliance with antihypertensive therapy isslightly less in blacks than in whites, although when socio-economic status is taken into account the black-white difference in compliance disappears (HDFP Cooperative Group, 1978).

As judged by the experience in the HDFP, $\& a$ large U.S.A. trial of the benefits of antihypertensike $\infty$ therapy), mortality is reduced more in blacks th in whites by treatment. This was due, perhaps, to응 the difference in blood pressure control between the intensive treatment group and the comparisono groups, being greater in blacks than in whites $\frac{\Omega}{\varnothing}$ (HDFP Cooperative Group, 1979).

\section{Secondary hypertension in blacks and whites}

There is nothing to suggest that secondary? hypertension is more frequent in blacks than in whites. Hypertension is much more frequent in blacks; therefore, fewer of the patients will have 3 . specific causes for their hypertension. As the blackwhite difference in hypertension is more pronounced for higher pressure, detection of specific causes of severe hypertension is much more likely in whites. For instance, $32 \%$ of white patients with accelerated or malignant hypertension had renovascular disease $>$ (43\% of those receiving arteriography) compared to $4 \%$ of blacks $(7 \%$ of those arteriographed) N (Davis et al., 1979).

\section{Discussion}

There seems to be no question that throughout the United States of America blacks, overall, havec more hypertension and hypertensive cardiovascular disease than do whites. Socio-economic factors are $\stackrel{\mathcal{P}}{+}$ associated with marked differences in the prevalence $\frac{T}{T}$ of hypertension. It is impossible at the moment to $\frac{\vec{D}}{\mathbb{D}}$ 
say whether there is a genetic, as well as an environmental cause of the black-white differences, although a comparison of blacks in more favoured socioeconomic status with rural whites in at least one study showed abolition of the differences. Difference in the sodium-potassium ratio of foods usually consumed has been found in 2 studies and could be causal, as there is clear animal evidence and suggestive human evidence that potassium is natriuretic and can lower blood pressure. Furthermore, the higher costs of high potassium foods, at least in the United States of America, explains why poorer people have a lower potassium consumption. The differences in pathophysiology between black and white hypertensives are fairly consistent; the majority of these are compatible with the assumption that blacks are relatively volume expanded with lower plasma renin activity, higher blood volume, lower kallikrein excretion and, possibly, lower sympathetic nervous system activity. These differences could reflect a basic difference in pathophysiology but on the other hand they may represent the consequences of greater renal damage due to more prolonged hypertension at the time the patients are studied.

A dogmatic and Procrustean interpretation of the above data is that early hypertension in the blacks is produced by a diet with a high $\mathrm{Na} / \mathrm{K}$ ratio. The early and prolonged hypertension produces changes in the renal vasculature that impede sodium excretion, leading both to more hypertension and homoeostatic lowering of renin secretion, kallikrein excretion, and sympathetic nervous system activity. Therefore, hypertension in the black exemplifies how environmental influences affect the prevalence of hypertension, how hypertension produces physiological changes that perpetuate hypertension by interfering with sodium excretion, and how associated risk factors influence cardiovascular morbidity, but sheds no light on genetic aberrations which may lead to hypertension.

An alternative interpretation of the evidence is that hypertension in the black exemplifies how genetic factors interfere with sodium excretion and therefore produce hypertension if an amount of sodium is ingested which would not produce hypertension in an individual who can more easily excrete sodium.

Perhaps the truth lies between the 2 poles. Suppose blacks have a genetic abnormality which interferes with sodium excretion, and commonly in the Western world eat a low potassium, perhaps slightly high sodium diet. Then both genetic and environmental factors would summate and produce the catastrophic amount of hypertension found in blacks from deprived backgrounds.

As noted above, the evidence is unclear as to whether blacks or whites have more cardiovascular disease for a given level of hypertension. The simplest explanation is that there is no real difference if other cardiovascular risk factors are taken into account.

As there are minimal, if any, differences in compliance between black and whites to antihypertensive medication, and marked improvement in cardiovascular mortality after antihypertensive therapy in blacks, there is a clear imperative to offer enthusiastic antihypertensive therapy to all black hypertensives.

\section{Acknowledgments}

This study was supported in part by Clinical Research Grant, NIH-DRR-MO1-RR00626, Effect of Dietary Modification on High Blood Pressure Grant, NHLBI-1 RO1-HL24369, and by Grant HE10721 from the United States Public Health Service.

\section{References}

AshCroft, M.T. \& DesaI, P. (1978) Blood pressure and mortality in a rural Jamaican community. Lancet, i, 1167.

BOYLE Jr, E. (1970) Biological patterns in hypertension by race, sex, body weight, and skin color. Journal of the American Medical Association, 213, 1637.

Cruickshank, J.K. \& Beevers, D.G. (1980) Is blood pressure really 'worse' in black people? Lancet, ii, 371.

Davis, B.A., Crook, J.E., Vestal, R.E. \& Oster, J.A. (1979) Prevalence of renovascular hypertension in patients with grade III or IV hypertensive retinopathy. New England Journal of Medicine, 301, 1273.

Deubner, D.C., Tyroler, H.A. \& Cassell, J.C. (1975) Attributable risk and population ascribable fraction of death associated with hypertension in a bioracial population. Circulation, 52, 901.

Harburg, E., Schork, M.A., Erfurt, J.C., Schuller, W.J. \& CHAPE, C. (1977) Heredity, stress and blood pressure. A family set method-II Results of blood pressure measurement. Journal of Chronic Disease, 30, 649.

Helmer, O.M. \& Judson, W.E. (1968) Metabolic studies on hypertensive patients with suppressed plasma renin activity not due to hyperaldosteronism. Circulation, 38, 965.

Hypertension Detection and Follow-up Program CoOPERATIVE Group (1977) Race, education and prevalence of hypertension. American Journal of Epidemiology, $106,351$.

Hypertension Detection and Follow-up Program CoOperative Group (1978) Patient participation in a hypertension control program. Journal of the American Medical Association, 239, 1507.

Hypertension Detection and Follow-up Program CoOperative Group (1979) Five-year findings of the Hypertension Detection and Follow-up Program. II. Mortality by race-sex and age. Journal of the American Medical Association, 242, 2572.

James, S.A. \& KLeinbaum, D.G. (1976) Socioecologic stress and hypertension related mortality rates in North Carolina. American Journal of Public Health, 66, 354.

Jones, D.H., Hamilton, C.A. \& Reid, J.L. (1978) Plasma noradrenaline, age and blood pressure in a population study. Clinical Science and Molecular Medicine, 55, 73.

Keil, J.E., Tyroler, H.A., SAndifer, S.W. \& Boyle, E. (1977) Hypertension: effect of social class and racial admixture. American Journal of Public Health, 67, 634.

LANGford, H.G., Watson, R.L. \& Douglas, B.H. (1968) 
Factors affecting blood pressure in population groups. Transactions of the Association of American Physicians, $81,135$.

Levy, S.B., Frigon, R.P. \& Stone, R.A. (1979) Plasma dopamine beta-hydroxylase activity and blood pressure variability in hypertensive man. Clinical Endocrinology, 11, 187.

Levy, S.B., Lilley, J.J., Frigon, R.P. \& Stone, R.A. (1977) Urinary kallikrein and plasma renin activity as determinants of renal blood flow: the influence of race and dietary sodium intake. Journal of Clinical Investigation, 60, 123.

Levy, Steven B., Talner, L.B., Coll, M.N., Holle, R. \& StONE, R.A. (1978) Renal vasculature in essential hypertension: racial differences. Annals of Internal Medicine, 88, 12.

Luft, G.C., Grim, C.E., Higgins, J.T. \& Weinberger, W.H. (1977) Differences in response to sodium administration in normotensive white and black subjects. Journal of Laboratory and Clinical Medicine, 90, 555.

Mclean, C.J., Adams, M.S., Leyshon, W.C., Workman, P.L., Reed, T.E., Gershowitz, H. \& Weitramp, L.R.
(1974) Genetic studies on hybrid population. III. Blood pressure in an American black community. American尺 Journal of Human Genetics, 26, 614.

Mitus, I.A., Holle, R., Levy, S.B. \& Stone, R.A. (1979) Racial analysis of the volume-renin relationship in human hypertension. Archives of Internal Medicine, 139, 157.

Russell, R.P., Mari, A.T. \& Richter, R.D. (1972) Adrenale cortical adenomas and hypertension. Medicine, 51, 211.

Sever, P.S., Peart, W.S., Meade, T.W., Davies, B. \& $\frac{\omega}{7}$ TuNBRIDGE, R.D.G. (1978) Are racial differences in $\mathbb{\Phi}$ essential hypertension due to different pathogenetic mechanisms? Clinical Science and Molecular Medicine, œ 55, 383.

Voors, A.W., Berenson, G.S., Dalfreres, E.R., Webber, L.S. \& SHULER, S.E. (1979) Racial differences in blood pressure control. Science, 204, 1091.

Watson, R.L., Langford, H.G., Abernethy, J., Barnes, T.Y. \& WATSON, M.J. (1980) Urinary electrolytes, bodye weight, and blood pressure. Pooled cross-sectional results 3 . among four groups of adolescent females. Hypertension, 2 (suppl. 1), 93. 


\section{CORRIGENDUM}

Postgraduate Medical Journal

\section{December 1981 Vol. 57 No. 674}

Page 749, second paragraph of right hand column. The final sentence should read, 'However when only individuals with a weight equal to 1 to 1.9 times ideal weight were considered, the influence of education on BP was abolished with the exception of black men (HDFP) Cooperative Group, 1977)'. 